\title{
PENGARUH TERAPI KELOMPOK TERAPEUTIK TERHADAP PENINGKATAN PERKEMBANGAN PSIKOSOSIAL DAN EMOSI ANAK REMAJA
}

\author{
The Effect Of Therapeutic Group Therapy On \\ Increasing The Psychosocial And Emotional Development Of Adolescents
}

\author{
Arifuddin $^{1 *}$, Helena Pangaribuan ${ }^{2}$ \\ 1,2Politeknik Kesehatan Kemenkes Palu \\ "Email korespondensi : arifhamid0369@gmail.com
}

\begin{abstract}
Abstrak
Pendahuluan : Usia Remaja merupakan masa transisi dari masa anak-anak menuju masa dewasa yang dihadapkan pada berbagai tantangan dan masalah perkembangan. Kegagalan dalam perkembangannya dapat membentuk kepribadian Social Anxiety Disorders pada saat dewasa yang ditandai dengan adanya gangguan mental dan gangguan kepribadiaan. Terapi kelompok terapeutik merupakan salah satu cara untuk membantu menyelesaikan permasalahan pada masalah tumbuh kembang pada anak dengan cara stimulasi yang sesuai perkembangan remaja. Penelitian ini bertujuan mengidentiifikasi pengaruh terapi kelompok terapeutik terhadap peningkatan perkembangan psikososial dan emosi anak remaja. Metode : Desain yang digunakan dalam penelitian ini adalah Quasi eksperimen dengan pendekatan pre test - pos test control group. Populasi dalam penelitian ini adalah semua siswa SMPN 9 Palu. Jumlah sampel sebanyak 50 dengan metode sampel purposive sampling. Instrument peneltian menggunakan kuesioner psikososial dan emosi. Uji statistik menggunakan uji Paired T Test. Hasil : Hasil penelitian menunjukkan bahwa terdapat perbedaan skor perkembangan psikosial sebelum dan sesudah diberikan terapi kelompok terapeutik dengan p-value 0,000 , terdapat perbedaan skor perkembangan emosi sebelum dan sesudah diberikan terapi kelompok terapeutik dengan p-value 0,000. Kesimpulan : Terapi kelompok terapeutik dapat meningkatkan perkembangan psikososial dan emosi pada anak remaja. Saran : Perawat dapat menerapkan terapi kelompok terapeutik pada anak remaja untuk meningkatkan kualitas asuhan keperawatan kesehatan jiwa di masyarakat
\end{abstract}

Kata Kunci :Terapi kelompok terapeutik; Perkembangan psikososial; perkembangan emosi; remaja.

\begin{abstract}
Introduction : Adolescence is a transition period from childhood to adulthood that is faced with various challenges and developmental problems. Failure in its development can shape the personality of Social Anxiety Disorders in adulthood which is characterized by mental disorders and personality disorders. Therapeutic group therapy is one way to help solve problems in children's growth and development problems using appropriate stimulation for adolescent development. This study aims to identify the effect of therapeutic group therapy on improving the psychosocial and emotional development of adolescents. Methods: The design used in this study is a quasiexperimental approach with a pre-test - post-test control group approach. The population in this study were all students of SMPN 9 Palu. The number of samples is 50 with the purposive sampling method. The research instrument used a psychosocial and emotional questionnaire. Statistical test using Paired T-Test. Results: The results showed that there were differences in psychosocial development scores before and after being given therapeutic group therapy with a p-value of 0.000 , there were differences in emotional development scores before and after being given therapeutic group therapy with a p-value of 0.000 . Conclusion: Therapeutic group therapy can improve psychosocial and emotional development in adolescents. Suggestion: Nurses can apply therapeutic group therapy to adolescents to improve the quality of mental health nursing care in the community
\end{abstract}

Keywords: Therapeutic group therapy; Psychosocial development; emotional development; teenager.

\section{https://doi.org/10.33860/mnj.v2i1.440}




\section{Pendahuluan}

Usia Remaja merupakan masa transisi dari masa anak-anak menuju masa dewasa yang dihadapkan pada berbagai tantangan dan masalah perkembangan. Pada periode ini terjadi perubahan yang kompleks. Perubahan tersebut meliputi biologis, kognitif, psikososial, moral, psikoseksual, emosi, bakat dan kreatifitas ${ }^{1}$. Kegagalan pada satu tahap tumbuh kembang dapat mempengaruhi tahap tumbuh kembang berikutnya.

Data WHO (2009) menyatakan 1 dari 5 orang di dunia yang berusia 13-18 tahun 21, $4 \%$ gangguan jiwa selama proses kehidupannya. Estimasi yang mengalami gangguan jiwa sebanyak $13 \%$ pada anak usia 8 -15 tahun. Kegagalan dalam upaya perbaikan akan mengakibatkan resiko jumlah anak dan remaja yang mengalami gangguan jiwa akan semakin bertambah $^{2}$. Oleh sebab itu perlu dilakukan pendekatan terhadap anak dalam menstimulasi perkembangan anak remaja untuk mempersiapkan anak remaja memasuki usia dewasa.

Gejolak emosi remaja bersifat agresif bahkan ke arah destruktif yaitu suka mengkritik dan mencemooh, mempunyai harga diri yang tinggi sehingga selalu optimistis ${ }^{3}$. Anak cenderung terlihat suka membantah, protes, cemas, takut, tidak mengikuti keinginan orang tua, meremehkan orang lain, selalu sibuk dengan kelompoknya, tidak mengerjakan tugas sekolah, tingkah lakunya sangat terikat oleh tujuan objektif dan mau menang sendiri ${ }^{4}$.

Kegiatan sekolah dapat menyebabkan remaja mengalami stres baik secara fisik, psikologis maupun sosial. Desmita (2009) menyatakan bahwa 10-30 \% anak mengalami masalah cemas, stres, berkelahi, berbohong dan takut ke sekolah. anak remaja belum mampu secara tepat menyelesaikan konflik, anak remaja lebih rentan untuk berperilaku agresif dan emosional sehingga dapat menghambat perkembangan ke masa dewasa ${ }^{4}$. periode ini dianggap sebagai periode kritis dimana kualitas stimulasi harus diatur sebaik mungkin agar dapat mencapai perkembangan kesehatan yang optimal ${ }^{5}$.

Pemberian stimulasi di lingkungan sekolah sangat efektif mengoptimalkan perkembangan remaja karena hampir sepertiga waktu anak remaja dalam satu hari dihabiskan di sekolah ${ }^{6}$. Menurut Simone \& Onrust (2016) Lingkungan sekolah merupakan lembaga pendidikan formal yang melaksanakan program bimbingan, pengajaran, latihan dan membantu siswa agar mampu mengembangkan potensinya. Melalui promosi kesehatan mental dapat meningkatkan perkembangan anak remaja yang diharapkan dapat mengatasi gejolak emosi kearah destruktif dan mencegah resiko penggunaan narkoba, merokok dan alcohol. Terapi kelompok terapeutik merupakan salah satu cara untuk membantu menyelesaikan permasalahan pada masalah tumbuh kembang ${ }^{8,6}$. Terapi kelompok terapeutik memberikan kesempatan kepada anggotanya untuk saling berbagi pengalaman untuk membantu menyelesaikan masalah dengan mengajarkan cara yang efektif untuk mengendalikan stres emosional ${ }^{9}$.

Hasil studi pendahuluan yang dilakukan peneliti di SMPN 9 Palu dengan guru didapatkan informasi sering terjadi perkelahian didalam kelas dan diluar kelas, siswa merokok dan tidak hadir tanpa surat keterangan. Hasil observasi siswa kelas 7 dan 8 menunjukkan siswa banyak diam dan kurang kooperatif dengan temannya, berbicara kasar dan kurang percaya diri. Berdasarkan uraian di atas perlu dilakukan kajian tentang "Pengaruh Terapi Kelompok Terapeutik terhadap peningkatan perkembangan psikososial dan emosional remaja di SMP Negeri 9 Palu "

\section{Metode}

Jenis penelitian ini adalah kuantitatif dengan desain penelitian Quasi eksperimen dengan pendekatan pre test - pos test control group. Penelitian ini dilakukan di SMP Negeri 9 Jalan Zebra Star Palu. Populasi penelitian ini adalah semua siswa SMPN 9 Palu. Sampel pada penelitian ini adalah siswa yang memenuhi kriteria inklusi sebanyak 50 orang. Waktu penelitian 13 Oktober s/d 17 November 2019. Tehnik pengambilan sampel menggunakan purposive sampling.

Penelitian ini peneliti membagi sampel menjadi 2 kelompok yaitu kelompok perlakuan dan kelompok control. Kelompok perlakuan diberikan terapi kelompok terapeutik, dimana 1 kelompok terdiri dari 9 orang yang terdiri dari 7 sesi dengan durasi 45-60 menit untuk setiap 
sesi. Sesi 1 : konsep stimulasi, sesi 2 : stimulasi aspek motoric, sesi 3 : stimulasi aspek kognitif dan Bahasa, sesi 4 : stimulasi aspek emosi dan kepribadian, sesi 5 : stimulasi aspek moral dan spiritual, sesi 6 : stimulasi aspek psikososial dan sesi 7 : sharing pengalaman TKT. sedangkan kelompok control diberikan penyuluhan kesehatan tentang perkembangan psikososial dan emosi pada remaja.

Pengolahan data melalui empat tahapan yaitu editing, coding, processing, dan cleaning. Analisa data penelitian meliputi analisis univariat untuk mengidentifikasi variabel independen maupun dependen. Selanjutnya, analisis bivariat dengan menggunakan uji paired t-test, untuk mengetahui perbedaan mean pada kelompok perlakuan dan kelompok control.

\section{Hasil}

Hasil penelitian adalah sebagai berikut :

Tabel 1 Karakteristik Responden

\begin{tabular}{llcccc}
\hline \multirow{2}{*}{ Variabel } & Kategori & \multicolumn{2}{c}{$\begin{array}{c}\text { Kelompok } \\
\text { perlakuan } \\
(\mathbf{N = 5 0 )}\end{array}$} & \multicolumn{2}{c}{$\begin{array}{c}\text { Kelompok } \\
\text { kontrol } \\
(\mathbf{N = 5 0 )}\end{array}$} \\
\cline { 3 - 6 } & & $\mathbf{N}$ & $\mathbf{\%}$ & $\mathbf{N}$ & $\mathbf{\%}$ \\
\hline Usia & 12 tahun & 20 & 40 & 20 & 40 \\
& 13 tahun & 10 & 20 & 10 & 20 \\
& 14 tahun & 15 & 30 & 15 & 30 \\
& 15 tahun & 5 & 10 & 5 & 10 \\
\hline Jenis & Total & $\mathbf{5 0}$ & $\mathbf{1 0 0}$ & $\mathbf{5 0}$ & $\mathbf{1 0 0}$ \\
\hline Kelamin & Laki-laki & 30 & 60 & 20 & 40 \\
\hline Pendidikan & Perempuan & 20 & 40 & 30 & 60 \\
orang tua & Total & $\mathbf{5 0}$ & $\mathbf{1 0 0}$ & $\mathbf{5 0}$ & $\mathbf{1 0 0}$ \\
& SD & 0 & 0 & 0 & 0 \\
& SMP & 0 & 0 & 0 & 0 \\
& SMA & 30 & 60 & 30 & 60 \\
& Perguruan & 20 & 40 & 20 & 40 \\
\hline & Tinggi & & & & \\
\hline & Total & $\mathbf{5 0}$ & $\mathbf{1 0 0}$ & $\mathbf{5 0}$ & $\mathbf{1 0 0}$ \\
\hline
\end{tabular}

Berdasarkan tabel 1 dapat diketahui karakteristik usia anak sekolah pada kelompok perlakuan sebagian besar usia 12 tahun sebanyak 20 orang (40\%) dan pada kelompok kontrol usia 12 tahun (40\%). Jenis kelamin pada kelompok perlakuan sebagian besar lakilaki sebanyak 30 orang $(60 \%)$ dan pada kelompok kontrol jenis kelamin laki-laki dan perempuan masing-masing 30 orang $(60 \%)$. Pendidikan orang tua pada kelompok perlakuan sebagian besar SMA sebanyak 30 orang $(60 \%)$ dan pada kelompok kontrol SMA dan
Perguruan Tinggi masing-masing 30 orang $(60 \%)$.

Tabel 2 Tabel uji normalitas data perkembangan psikososial pada kelompok perlakuan dan kelompok control

\begin{tabular}{lcll}
\hline Kelompok & N & Parameter & P Value \\
\hline $\begin{array}{l}\text { Perlakuan } \\
\text { (pre) }\end{array}$ & 18 & $\begin{array}{l}\text { Shapiro- } \\
\text { wilk }\end{array}$ & 0,385 \\
$\begin{array}{l}\text { Perlakuan } \\
\text { (post) }\end{array}$ & 18 & $\begin{array}{l}\text { Shapiro- } \\
\text { wilk }\end{array}$ & 0,410 \\
Kontrol (pre) & 18 & $\begin{array}{l}\text { Shapiro- } \\
\text { wilk }\end{array}$ & 0,269 \\
Kontrol (post) & 18 & $\begin{array}{l}\text { Shapiro- } \\
\text { wilk }\end{array}$ & 0,233 \\
\hline
\end{tabular}

Berdasarkan tabel 5.2 hasil uji normalitas dari test Normality of Shapiro-wilk dengan tingkat kepercayaan $95 \%$ data perkembangan psikososial sebelum intervensi $(0,385)$ dan sesudah intervensi $(0,410)$ pada perlakuan dan kelompok kontrol sebelum intervensi $(0,269)$ dan sesudah intervensi $(0,233)$, didapatkan sebaran normal dengan $\mathrm{p}>0,05$. Hasil uji homogenitas dari Test of Homogenity Variance dengan tingkat kepercayaan $95 \%$ didapatkan sebaran normal dengan $p>0,05$, oleh karena data sebaran normal maka uji yang digunakan adalah uji $\mathrm{T}$ test berpasangan dan tidak berpasangan

Tabel 3 Perubahan perkembangan psikososial sebelum dan sesudah intervensi pada kelompok perlakuan dan kelompok control

\begin{tabular}{|c|c|c|c|c|c|c|}
\hline \multirow{2}{*}{$\begin{array}{l}\text { Variabel } \\
\text { motorik }\end{array}$} & \multirow{2}{*}{$\mathrm{n}$} & \multirow{2}{*}{ Mean } & \multirow{2}{*}{$\mathrm{SD}$} & \multirow{2}{*}{$\begin{array}{l}\text { Perbedaan } \\
\text { Mean } \pm \\
\text { SD }\end{array}$} & \multicolumn{2}{|c|}{$\begin{array}{c}\text { Hasil uji t } \\
\text { berpasangan }\end{array}$} \\
\hline & & & & & $\mathrm{t}$ & $\begin{array}{c}\mathrm{p} \\
\text { value }\end{array}$ \\
\hline $\begin{array}{l}\text { Intervensi } \\
\text { (pret test) }\end{array}$ & 50 & 22,61 & 2,91 & \multirow{2}{*}{$\begin{array}{c}4,66 \pm \\
2,37\end{array}$} & \multirow{2}{*}{8,332} & \multirow{2}{*}{0,000} \\
\hline $\begin{array}{l}\text { Intervensi } \\
\text { (post test) }\end{array}$ & 50 & 27,28 & 2,13 & & & \\
\hline $\begin{array}{c}\text { Kontrol } \\
\text { (pret test) }\end{array}$ & 50 & 21,33 & 2,61 & \multirow[t]{2}{*}{$\begin{array}{c}0,72 \pm \\
1,56\end{array}$} & \multirow[t]{2}{*}{1,959} & \multirow[t]{2}{*}{0,67} \\
\hline $\begin{array}{c}\text { Kontrol } \\
\text { (post test) }\end{array}$ & 50 & 22,06 & 2.77 & & & \\
\hline
\end{tabular}

Berdasarkan tabel 3 pada kelompok perlakuan dapat diinterpretasikan Hasil uji T berpasangan (paired-sampel t test) menunjukkan nilai $\mathrm{t}_{\text {hitung }}$ 
sebesar 8,332 dan nilai signifikansi sebesar 0,000 , oleh karena $t_{\text {hitung }}>t_{\text {tabel }}(8,332>2,110)$ dan signifikansi lebih kecil dari 0,05 $(0,000<0,05)$, artinya ada perbedaan yang signifikan pada perkembangan psikososial anak usia sekolah antara sebelum dan sesudah diberi terapi kelompok terapeutik. Hal ini mengindikasikan bahwa terapi kelompok terapeutik dapat berpengaruh positif terhadap perubahan perkembangan psikososial (post test) lebih tinggi (Mean=27,28) dari pada (pre test $)($ Mean=22,61). Pada kelompok kontrol diinterpretasikan Hasil uji $\mathrm{T}$ berpasangan (paired-sampel T test) menunjukkan nilai $\mathrm{t}$ hitung sebesar 1,959 dan nilai signifikansi sebesar 0,67 , oleh karena $\mathrm{t}$ hitung $<\mathrm{t}$ tabel $(1,959<2,110)$ dan signifikansi lebih besar dari $0,05(0,67>0,05)$, artinya tidak ada perbedaan yang signifikan pada perkembangan anak usia sekolah antara sebelum dan sesudah diberi terapi kelompok terapeutik. Hal ini mengindikasikan bahwa penyuluhan kesehatan tidak berpengaruh positif terhadap perubahan perkembangan psikososial.

\section{Tabel 4 Perubahan perkembangan emosi sebelum dan sesudah intervensi pada kelompok perlakuan dan kelompok control}

\begin{tabular}{|c|c|c|c|c|c|c|}
\hline \multirow{2}{*}{$\begin{array}{l}\text { Variabel } \\
\text { motorik }\end{array}$} & \multirow{2}{*}{$\mathrm{n}$} & \multirow{2}{*}{ Mean } & \multirow{2}{*}{ SD } & \multirow{2}{*}{$\begin{array}{c}\text { Perbedaan } \\
\text { Mean } \pm \\
\text { SD }\end{array}$} & \multicolumn{2}{|c|}{$\begin{array}{c}\text { Hasil uji t } \\
\text { berpasangan }\end{array}$} \\
\hline & & & & & $\mathrm{t}$ & $\begin{array}{c}\mathrm{p} \\
\text { value }\end{array}$ \\
\hline $\begin{array}{l}\text { Intervensi } \\
\text { (pret test) }\end{array}$ & 50 & 47,44 & 5,30 & \multirow{2}{*}{$\begin{array}{c}9,06 \pm \\
5,12\end{array}$} & \multirow{2}{*}{7,493} & \multirow{2}{*}{0,000} \\
\hline $\begin{array}{l}\text { Intervensi } \\
\text { (post test) }\end{array}$ & 50 & 56,50 & 3,68 & & & \\
\hline $\begin{array}{c}\text { Kontrol } \\
\text { (pret test) }\end{array}$ & 50 & 48,50 & 5,70 & \multirow[t]{2}{*}{$\begin{array}{l}0,33 \pm \\
2,22\end{array}$} & \multirow[t]{2}{*}{0,636} & \multirow[t]{2}{*}{0,533} \\
\hline $\begin{array}{c}\text { Kontrol } \\
\text { (post test) }\end{array}$ & 50 & 48,83 & 5,19 & & & \\
\hline
\end{tabular}

Berdasarkan tabel 5.5 pada kelompok intervensi dapat diinterpretasikan Hasil uji T berpasangan (paired -sampel $T$ test) menunjukkan nilai $\mathrm{t}$ hitung sebesar 7,493 dan nilai signifikansi sebesar 0,000 , oleh karena $t$ hitung $>\mathrm{t}$ tabel $(7,493>2,110)$ dan signifikansi lebih kecil dari $0,05(0,000<0,05)$, artinya ada perbedaan yang signifikan pada perkembangan emosi anak usia sekolah antara sebelum dan sesudah diberi terapi kelompok terapeutik. Hal ini mengindikasikan bahwa terapi kelompok terapeutik dapat berpengaruh positif terhadap perubahan perkembangan emosi (post test) lebih tinggi (Mean=56,55) dari pada (pre test) (Mean=47,44). Pada kelompok kontrol dapat diinterpretasikan Hasil uji $\mathrm{T}$ berpasangan (paired-sampel $T$ test) menunjukkan nilai $\mathrm{t}$ hitung sebesar 0,636 dan nilai signifikansi sebesar 0,533, oleh karena $\mathrm{t}$ hitung $>\mathrm{t}$ tabel $(0,636<2,110)$ dan signifikansi lebih besar dari $0,05(0,533>0,05)$, artinya tidak ada perbedaan yang signifikan pada perkembangan emosi anak usia sekolah antara sebelum dan sesudah diberkan penyuluhan kesehatan. Hal ini mengindikasikan bahwa penyuluhan kesehatan tidak berpengaruh positif terhadap perubahan perkembangan emosi.

\section{Pembahasan}

\section{Perubahan perkembangan kemampuan psikososial sebelum dan sesudah dilakukan terapi kelompok terapeutik.}

Pelaksanaan terapi kelompok terapeutik ini anak dibagi menjadi 2 kelompok, dimana satu kelompok terdiri dari 9 orang serta lama sesi 60-90 menit sebanyak 7 sesi. Keadaan kondisi memungkinkan terapi kelompok terapeutik berjalan efektif dan anak mempunyai cukup waktu untuk belajar, saling berbagi pengalaman tentang stimulasi perkembangan anak dan mempraktekkan secara langsung stimulasi perkembangan psikosial dan emosi yang benar pada anak dalam kelompok.

Kegiatan terapi kelompok terapeutik diawali dengan konsep stimulasi perkembangan anak usia sekolah (fase identitas ). Penjelasan disertai contoh oleh Perawat pada anggota kelompok tentang ciri-ciri anak usia sekolah yang produktif dan yang tidak produktif, kemudian dilanjutkan anak mengisi daftar ciriciri anak yang produktif, tidak produktif dan ciri perkembangan masing-masing anggota kelompok sesuai atau tidak dengan perkembangannya sehingga anak tahu sampai dimana perkembangan dirinya. Kondisi belajar yang cukup dan ada kesempatan untuk mempraktekkan langsung cara stimulasi mendukung anak untuk meningkatkan 
kemampuan perkembangan psikososial pembentukan identitas diri mengenal kemampuan fisik ,kognitif dan kekurangan diri sendiri,hubungan social (saling menghargai atau menghormati orang lain) dan kemandirian.

Aspek psikososial anak berperan dalam peningkatan aspek kognitif dan afektif, dengan melatih keterampilan gerak, tubuh akan menjadi sehat, anak menjadi aktif dan pola fikir berkembang. Peningkatan perkembangan psikososial anak usia remaja pada kelompok perlakuan dapat disimpulkan sebagai suatu proses belajar diantara anggota melalui terapi kelompok terpaeutik. Sesuai dengan teori (Towsend, 2014) menyatakan bahwa terapi kelompok terapeutik adalah memberikan kesempatan pada setiap anggotanya untuk saling membantu satu dengan yang lain, menemukan cara menyelesaikan tugas/masalah dengan mengajarkan cara yang efektif untuk mengendalikan stress $^{10}$. Terapi kelompok terapeutik bertujuan mengembangkan empati dan kerja sama diantara sesama kelompok yaitu saling memberikan penguatan untuk membentuk perilaku yang adaptif sehingga tumbuh kembang anak dapat berjalan dengan normal.

Terapi kelompok terapeutik yang diberikan adalah melakukan stimulasi perkembangan psikososial untuk menumbuhkan kepercayaan diri yang positif ${ }^{11}$. Berdasarkan karakteristik jenis kelamin pada kelompok perlakuan sebagian besar laki-laki 30 orang $(60 \%)$ dan kelompok kontrol perempuan masing-masing 30 orang $(50 \%)$. Menurut papalia , Old \& Fieldman (2009) menyatakan tidak ada perbedaan antara jenis kelamin laki-laki dan perempuan dalam melaksanakan stimulasi perkembangan psikososial ${ }^{12}$. Karakteristik pendidikan orang tua pada kelompok perlakuan sebagian besar SMA adalah jenjang pendidikan dimana pendidikan orang tua yang baik akan mendukung kemampuan anak dalam melaksanakan stimulasi perkembangannya dengan baik, kondisi ini karna pendidikan ibu sebagian besar adalah perguruan tinggi mungkin pengetahuan ibu akan lebih baik. Sesuai dengan pendapat yang mengatakan bahwa lingkungan (pekerjaan orang tua, pendidikan orang tua dan perceraian orang tua) sangat berpengaruh pada perkembangan anak $^{13}$. Menurut El Moussaoui \& Braster, 2011; stimulasi merupakan rangsangan yang diberikan kepada anak oleh lingkungannya. Stimulasi dapat diberikan setiap ada kesempatan melalui kegiatan dirumah dan diluar rumah/sekolah. Stimulasi yang tepat dapat mengoptimalkan perkembangan anak usia sekolah ${ }^{14}$.

\section{Perubahan perkembangan kemampuan emosi sebelum dan sesudah dilakukan terapi kelompok terapeutik.}

Kemampuan stimulasi yang baik membuat perkembangan emosi anak akan berkembang dengan maksimal. Sesuai dengan teori mengatakan stimulasi memegang peranan penting dalam perkembangan anak dan cara terbaik untuk mengembangkan kemampuan anak yang diberikan kepada setiap ada waktu/kesempatan baik di lingkungan keluarga dan sekolah ${ }^{14}$. Pada kelompok intervensi setiap anak masing-masing mendapat kesempatan untuk melakukan stimulasi. Stimulasi yang dilakukan oleh anak sendiri akan membuat anak merasa nyaman dan stimulasi dipandu oleh perawat.

Emosi merupakan motivator perilaku dalam kehidupan seseorang dan juga dapat mengganggu perilaku manusia. Kemampuan mengontrol emosi diperoleh anak dari lingkungan keluarga,teman sebaya dan sekolah. Emosi yang tidak stabil merupakan salah satu masalah pada perkembangan anak usia sekolah. antara lain : gejolak emosi ke arah yang destruktif (agresif), gangguan mental emosional, berkelahi, takut kesekolah dan merasa rendah diri bila tidak mampu mengembangkan kemampuan psikososialnya. Masalah yang terjadi bila tidak ditangani mempunyai pengaruh terhadap perkembangan jiwa pada anak dimasa yang akan datang ${ }^{8}$.

Hasil penelitian menunjukkan bahwa indikator yang paling dipengaruhi oleh terapi kelompok terapeutik malu,rasa ingin tahu dan marah dimana ketika masing-masing anak tidak 
menolak untuk melaksanakan kegiatan, berusaha mengerjakan dan bertanya, kondisi tersebut menunjukkan anak sudah dapat mengontrol emosi dan kepercayaan diri anak semakin baik. Hal tersebut sesuai dengan pendapat yang mengatakan pemberian stimulasi yang baik akan sangat berpengaruh dalam pendidikan dan perkembangan anak dimasa yang akan datang. Orang tua, guru hendaknya mengetahui dan mampu memberikan stimulasi sesuai dengan usia perkembangan anak ${ }^{14}$.

Stimulasi perkembangan melalui terapi kelompok terapeutik adalah cara yang efektif untuk mengendalikan stres smosional dan meningkatkan potensi yang dimilki anak guna mencapai tumbuh kembang yang optimal sesuai dengan usia anak ${ }^{10}$. Terapi kelompok terapeutik dapat memberi kesempatan pada anak mengekspresikan emosi atau masalah perilaku dan saling memberikan umpan balik terhadap perilaku menjengkelkan atau menyenangkan, belajar toleransi dan mencegah sifat temperamental ${ }^{15}$.

Pada kelompok perlakuan, melalui terapi kelompok terapeutik setiap anak dilatih, diberikan pujian pada setiap keberhasilan yang dilakukan anak dan memotivasi anak bila belum berhasil melakukan kegiatan yang dilatih ${ }^{16}$. Pada usia anak yang lebih tua penguasaan keterampilan dan emosi lebih matang maka akan lebih mudah menyelesaikan masalah dengan realitas. Pemberian terapi kelompok terapeutik mampu meningkatkan perkembangan emosi dan kreaktifitas anak. Berdasarkan hasil observasi peneliti selama memimpin pelaksanaan terapi kelompok terapeutik peningkatan insiatif anak berkaitan erat dengan pemberian pujian yang dapat meningkatkan kepercayaan diri dan menstimulasi motivasi anak. Beberapa anak pada awalnya diam, menolak melakukan kegiatan karena masih takut, malu dan berkelahi akhirnya mau melakukan kegiatan karena ingin mendapatkan pujian.

Lingkungan sekolah merupakan lembaga pendidikan formal membantu siswa agar mampu mengembangkan potensinya ${ }^{17}$ Pemberian stimulasi di lingkungan sekolah sangat efektif mengoptimalkan perkembangan anak dimana Selama di sekolah anak dapat berinteraksi dengan teman sebaya dan guru dan hampir sepertiga waktu anak dalam satu hari dihabiskan disekolah ${ }^{4}$. Pemberian stimulasi yang baik adalah pemberian stimulasi yang disesuaikan dengan usia perkembangan anak. Dengan stimulasi ini, maka seluruh kemampuan anak baik kemampuan motorik dan emosi akan berkembang dengan baik.

\section{Kesimpulan}

Terapi kelompok terapeutik dapat meningkatkan perkembangan psikososial dan emosi pada anak remaja. Perawat dapat menerapkan terapi kelompok terapeutik pada anak remaja untuk meningkatkan kualitas asuhan keperawatan kesehatan jiwa di masyarakat

\section{Ucapan Terima Kasih}

Peneliti mengucapkan terima kasih kepada semua pihak yang telah membantu dan mendukung penelitian ini sehingga bias terlaksana dengan baik.

\section{Daftar Pustaka}

1. E.B H. Psikologi Perkembangan: Suatu Pendekatan Sepanjang Rentang Kehidupan. Jakarta: Erlangga; 2002.

2. Keliat BA, Daulima HN, P F. Manajemen Keperawatan Psikososial \& Kader Kesehatan Jiwa (CMHN). Jakarta: EGC; 2011.

3. Sacco RG. Re-Envisaging the Eight Developmental Stages of Erik Erikson: The Fibonacci Life-Chart Method (FLCM). J Educ Dev Psychol [Internet]. 2013 Mar 28;3(1). Available from: http://www.ccsenet.org/journal/index.php/ jedp/article/view/24725

4. Desmita. Psikologi Perkembangan Peserta Didik. Bandung: PT. Rosda Karya; 2009.

5. Videbeck LS. Buku ajar keperawatan jiwa. Bahasa Ind. Komalasari R, Hany A, editors. Jakarta: EGC; 2010.

6. Vreeman RC, Scanlon ML, Mwangi A, 
Turissini M, Ayaya SO, Tenge C, et al. A Cross-Sectional Study of Disclosure of HIV Status to Children and Adolescents in Western Kenya. Tang JW, editor. PLoS One [Internet]. 2014 Jan 27;9(1):e86616. Available from: https://dx.plos.org/10.1371/journal.pone.0 086616.

8. Shives R. Basic Concepts of PsychiatricMental Health Nursing. 8th ed. Philadephia: Lippincott Williams \& Wilkins; 2011.

9. Marmarosh CL, Tasca GA. Adult Attachment Anxiety: Using Group Therapy to Promote Change. J Clin Psychol [Internet]. 2013 Nov;69(11):1172-82. Available from: http://doi.wiley.com/10.1002/jclp.22044

10. Townsend C. Psychiatric Mental Health Nursing: Cocepts of Care in EvidenceBased Practice. six. Philadephia: F.A Davis Company; 2013.

11. Hall K, Grundy S. An analysis of Time 4U, a therapeutic group for women with postnatal depression. Community Pract [Internet]. 2014 Sep;87(9):25-8. Available from:

http://www.ncbi.nlm.nih.gov/pubmed/252 86739

12. Papalia ED, Old WS, Duskin R, Feldman. Human development (psikologi Perkembangan). 9th ed. Jakarta: Kencana; 2004.

13. Cláudia Rodrigues Sequeira de Figueiredo, Filomena Valadão Dias. Families: Influences in Children's Development and Behaviour, From Parents and Teachers' Point of View. J Psychol Res. 2012;2(12):693-705.

14. el Moussaoui N, Braster S. Perceptions and Practices of Stimulating Children's Cognitive Development Among Moroccan Immigrant Mothers. J Child Fam Stud [Internet]. 2011 Jun 21;20(3):370-83. Available from: http://link.springer.com/10.1007/s10826010-9401-8

15. Wood L., Haber J. Nursing research methods and critical appraisal for evidence-based practice. six. Missouri: Mosby Elsevier; 2006.
16. Stuart G. Principles and Practice of Psychiatric Nursing. 7th ed. Philadephia: Mosby; 2013.

17. Shelleby EC, Shaw DS, Cheong J, Chang $\mathrm{H}$, Gardner F, Dishion TJ, et al. Behavioral Control in At-Risk Toddlers: The Influence of the Family Check-up. J Clin Child Adolesc Psychol [Internet]. 2012 May 1;41(3):288-301. Available from: https://www.tandfonline.com/doi/full/10.1 080/15374416.2012.664814 